of circulation systems, opportunities for spatial preferences, way-finding and location qualities (Helsper, Johnson, Johnson, Rubba and Steiner, 1990; Arenibafo, 2016; Heitor, Nascimento, Tomé and Medeiros, 2013; Payne, 2007; Muñoz, 2009; Ambler, Webb, Hummell, Robertson, and Bailey, 2013) and disability (Asadi-Shekari, Moeinaddini and Shah, 2014). University campus open spaces (UCOS) are thus learning spaces, natural settings associated with strong public culture, the form and symbol of integrated social relationship, open air communal museums, spaces for social interactions and great public activities in their utilization (Lyndon, 2005; Mumford, 1938, 1969; McHarg, 1969; Geddes, 1906;Sahraiyanjahromi, 2017). From the utilization perspective, campus open spaces have also been described as being arenas that allow for different types of activities encompassing necessary, optional and social activities (Gehl, 1987; Woolley, 2003; Swensen and Stenbro, 2013; Nia, and Suleiman, 2017). UCOS include zoological and botanical gardens, recreation parks, pedestrian linear corridors, sports pitch, playgrounds, courtyards, parking, waterfronts, squares and plazas.

A zoological garden is a park containing plant material, but primarily designed for exhibiting wild animals (Alan, 2005). UZG functions as "a cultural showcase of animals and nature" and its design is "a consequence of human interpretations of the way in which the natural world should be perceived and presented" (Couper, 2013: 235). She posits that "zoological architecture is the physical embodiment of cultural understandings of scientific knowledge" and its interpretation exists within a cultural context of place and "the stages of zoological garden as a scientific endeavour had an interwoven relationship with architecture and place" (p. 235). UZGs focus on public education and nature conservation. Wolf and Tymitz (1979:17) argue that

"education includes observation,
perception, satisfying curiosity, making
sense out of one's observation or
experiences, accidental learning and, of
course, direct efforts to collect or offer
information"

According to Gewaily (2010), the five components of visitor experience in zoological gardens are "exploration, authenticity, aesthetics, education and recreation" (p. 45). UZGs are therefore of great academic significance while their recreational benefits as an opportunity for connection between their non-human nature and human nature. Fadamiro and Adedeji (2014) discovered that recreational benefits are contingent upon experiences of users and relies on the quality of the zoological gardens which depends on design considerations and parameters.

Although research concerns on UCOS include the design, designers, design decisions, materials and construction, maintenance and management, and the users, this research focuses on the users of university Zoological gardens (UZGs) which is a major category of UCOS. The users are at the receiving end of all the processes and are thus very central. It is therefore pertinent to carry out a study on UZGs with a prism of post-occupancy evaluation (POE) focussing on the users as a feedback into the design process towards developing framework for sustainable UZGs in South-west Nigeria.

\section{Statement of the Research Problem}

Designers of UCOS including UZGs are not fully acquainted with the performance of the spaces during their use. This leads to repetition of design mistakes and the university community using the spaces in ways that were only partially predicted (Watson and Thomson, 2005; Venkat, 2011 ; Cubukcu\&lsitan, 2011). As a result, the satisfaction of the users that can enable the formulation of EBD framework as a feed-back process is grossly missing.

\subsection{Research Questions, Objectives and Hypotheses}

Enhancing the performance of UZGs is contingent on users' satisfaction. This study's concern about users' satisfaction is guided by the following questions:

i What is the perception of quality and factors that underpin the users' satisfaction with the UZGs?

ii. What aspects of user satisfaction can inform design frameworks for UZGs?

Accordingly, the study seeks to:

i. Examine the perception of quality and factors influencing users' satisfaction with the

UZGs; and

ii. Develop design policy framework for UZGs.

To guide the study, the following hypotheses were formulated:

$\mathrm{Hol}_{\mathrm{l}}$ There is no significant difference in the perceptions of qualities of the UZGs among the Federal Universities in the study area. 
$\mathrm{H}_{2}$ Perception of quality is not contingent upon satisfaction of the users with the UZGs in the study area.

\section{Research Methodology}

The study area was the South-west region of Nigeria where the university campuses under study are located. The region comprises of the six states that make up the South-west Geopolitical zone of Nigeria (Figure 1).
Assessment of Zoological gardens of was carried out in the study. The study involved a survey research design with the use of questionnaires to evaluate the users' satisfaction with the Zoological gardens of the six Federal Universities in the study area. These include: University of Ibadan, Obafemi Awolowo University, Ile-Ife; University of Lagos; Federal University of Agriculture, Abeokuta; The Federal University of Technology, Akure and Federal University, Oye-Ekiti.

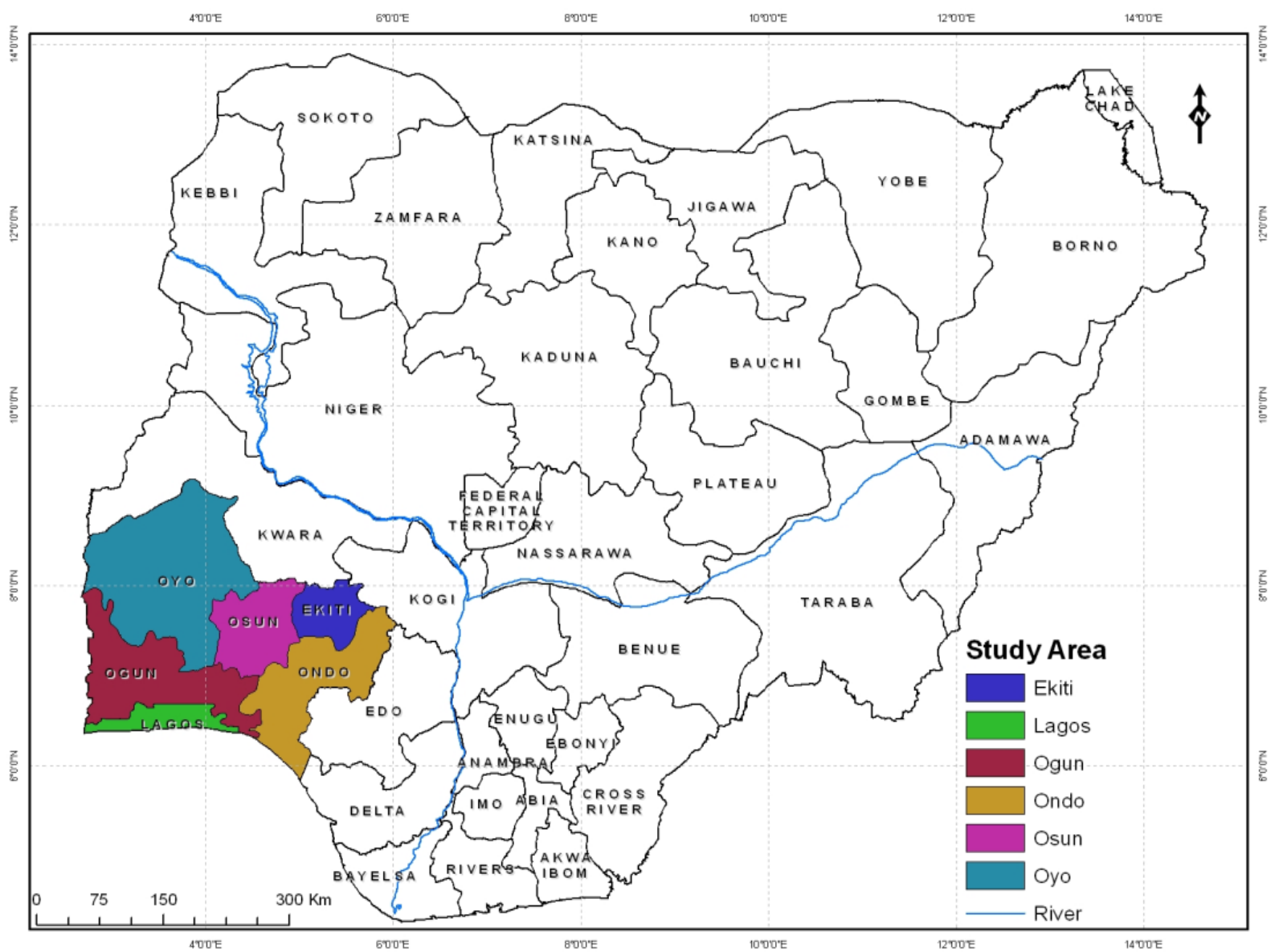

Figure 1. South West Map indicated on Map of Nigeria. Source:Faleyimu\&Agbeja(2012)

The choice of South-west was informed by the pioneering status of the region in university education in Nigeria hosting all typologies. since formal lessons are sought, the Federal Universities are the most formally designed with the same proprietorship and source of funding. The target population for the study were the students and members of staff who are the formal users of the gardens.

Structured questionnaire designed in multiple choice and Likert-type scale were used to collect necessary information about the respondents and other issues in the research questions, objectives and hypotheses. The questionnaire was subjected to pilot study carried out in order to perfect the research instrument and from the exercise, necessary adjustments were made. The pilot survey served as the model and dummy run of the main survey. Responses were coded with values from 1, 2, 3, 4 and 5 (Likert-type scale). This gave opportunity for ease of understanding and rationalization for statistical analyses. 
The data obtained were subjected to statistical analyses and interpretations by using descriptive (Frequency table, Percentages, Charts) and inferential (Chi square, Correlation tests, Regression analysis) statistics. The processed data was used to identify the statuses of the users, evaluate their perception of quality of the open spaces, analyse the relationship between their statuses and perception of qualities, examine the factors influencing their satisfaction and develop policy framework for Zoological gardens in Federal Universities in South-west Nigeria.
4. Data Presentation and Analysis

4.1 Status of the users and perception of quality of the UZGs

Table 1 reveals the status of the users of the UZGs. The users are disproportionately males (62.3\%) than females (37.7\%), mostly undergraduates $(87.5 \%)$ in the active age bracket of 19-45years (91.5\%). That all categories of users are adequately represented suggests the result should be adequate for generalization synthesis. Their perception of quality of the UZGs as shown in Table 2 are also reliable since they are well acquainted with the gardens and therefore their value-judgments can be upheld.

Table 1. Status of users of the UZGs in South-west Nigeria.

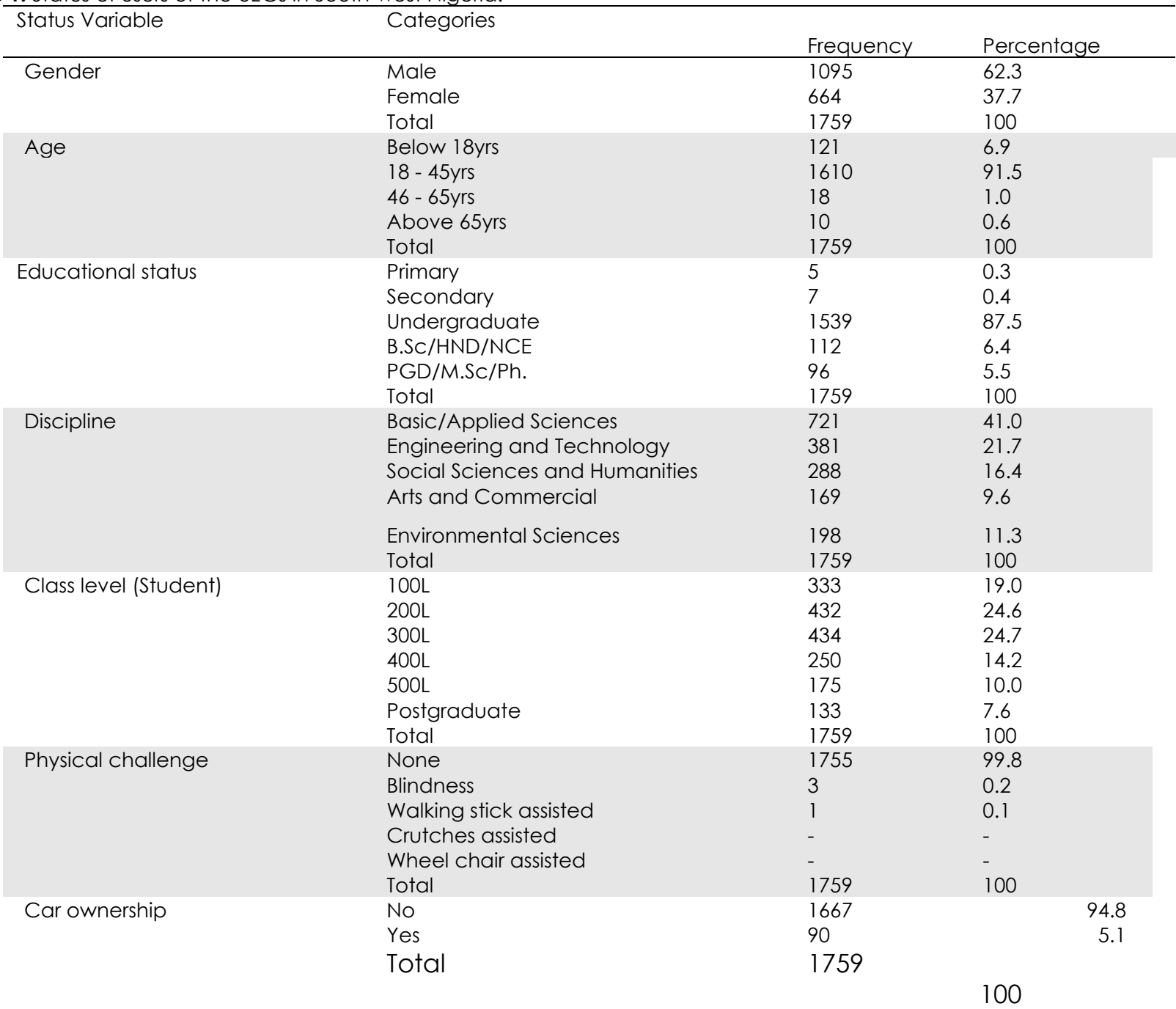

Table 2. Perception of qualities of UZGs of Federal Universities in South-west Nigeria.

\begin{tabular}{lll}
\hline Perception of quality & Freq. & $(\%)$ \\
\hline Poor & 285 & 16.2 \\
Scanty & 186 & 10.6 \\
Averagely set & 433 & 24.6 \\
Well set & 433 & 24.6 \\
Excellent & 333 & 18.9 \\
Total & 1670 & 94.4 \\
\hline
\end{tabular}




\subsection{Testing of Hypothesis}

Hol: There is no significant difference in the perceptions of qualities of the UZGs among the Federal Universities in the study area.

A Kruskal-Wallis $\mathrm{H}$ test was conducted to determine if the perceptions of qualities of the Zoological gardens is significantly different among the six Federal Universities and the results are as shown in Table 3. A Kruskal-Wallis $\mathrm{H}$ test showed that there was a statistically significant difference in the perceptions of qualities of the UZGs among the six Federal Universities. The results as shown in Figure 2 and explained with chart in Figure 3 indicate that Chi square, $x^{2}(d f, 5)=531.927, p=0.000$, with $a$ mean rank perception of quality score of 1207.46 for UI (Plate 1), 1022.45 for FUNAAB (Plate 2), 843.63 for OAU, 733.44 for FUTA (Plate 3), 604.23 for UNILAG (Plate 4) and 303.97 for FUOYE in descending order with UI having the best and FUOYE having the least. This implies the rejection of the Null Hypothesis $\mathrm{H}_{\circ} \mathrm{l}$ and implying that there is significant difference in the perceptions of qualities of the Zoological gardens among the Federal Universities in the study area.

To identify the pattern of the statistically significant differences in the perceptions of qualities of the Zoological gardens among the six Federal Universities, a Kruskal-Wallis post-hoc test was carried out. A Pairwise customised analysis result shows that all the Zoological gardens are perceived to be of different qualities except for OAU-FUTA $(p=.070)$ as shown in Figures 3.

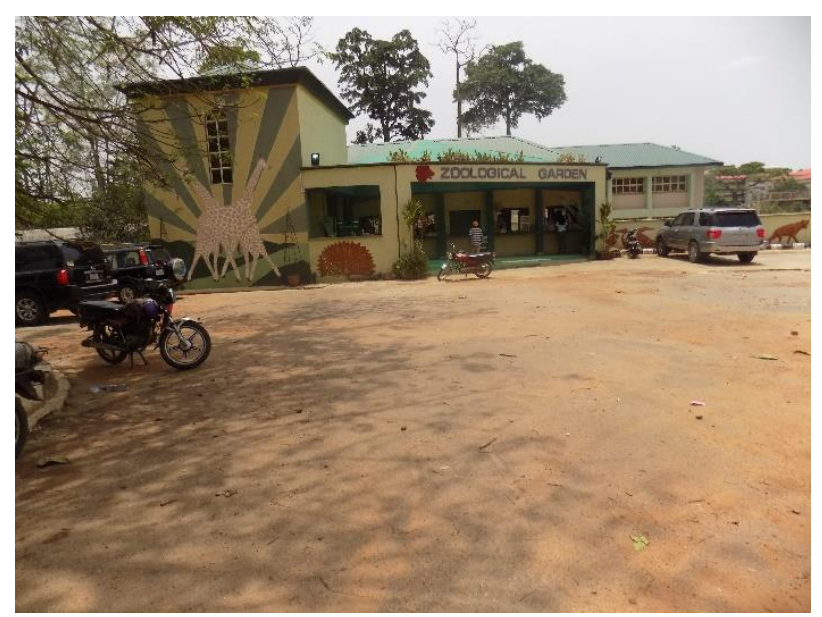

Plate 1. Entrance gate of University of Ibadan Zoological Garden, Ibadan, Nigeria

Source: Picture by authors, 2017

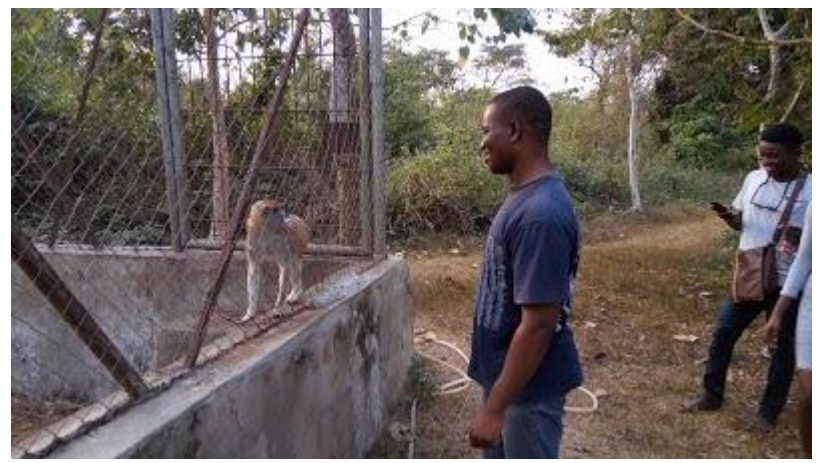

Plate 2. A pen in Federal University of Agriculture Abeokuta Zoological Garden, Nigeria

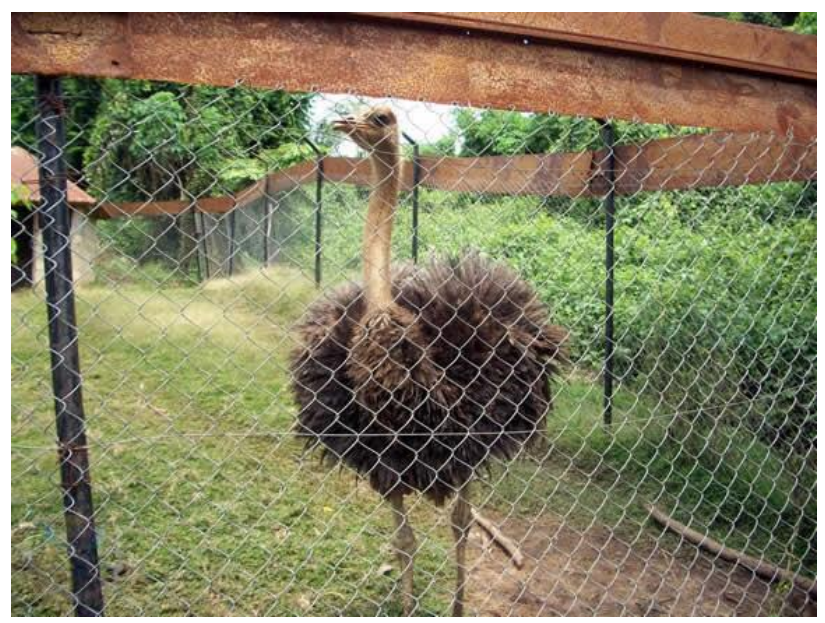

Plate 3. A pen in Federal University of Technology Akure Zoological Garden, Nigeria

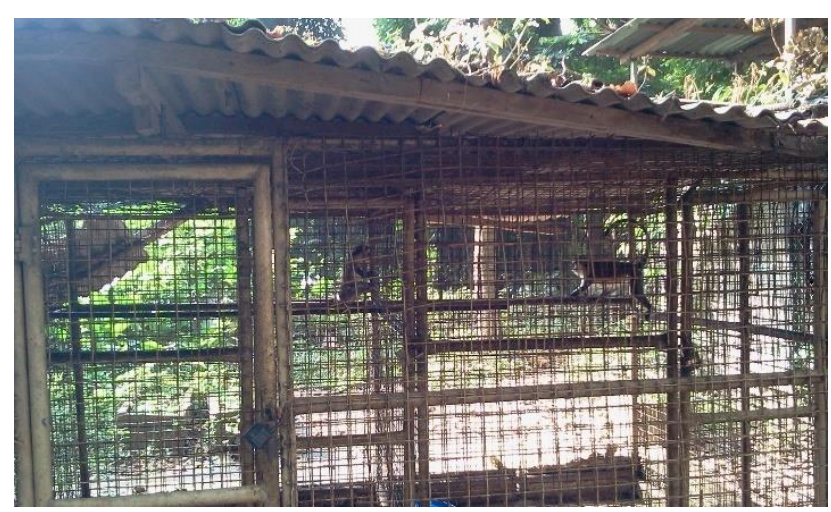

Plate 4. A pen in University of Lagos Zoological Garden, Lagos, Nigeria

Source: Picture by authors, 2017 
Table 3.Kruskal Wallis $\mathrm{H}$ Test of significant difference in the perceptions of qualities of theUniversity Zoological gardens in Southwest Nigeria.

\begin{tabular}{|c|c|c|c|c|c|}
\hline Null Hypothesis & $\begin{array}{c}\text { Chi } \\
\text { square }\end{array}$ & Asymp. Sig. & Decision & University & $\begin{array}{c}\text { Mean Rank Perception } \\
\text { of Quality Score }\end{array}$ \\
\hline \multirow{3}{*}{$\begin{array}{l}\text { There is no significant } \\
\text { difference in the } \\
\text { perceptions } \\
\text { of qualities of } \\
\text { Zoological }\end{array}$} & \multirow{5}{*}{531.927} & \multirow{5}{*}{0.000} & \multirow{5}{*}{$\begin{array}{l}\text { Reject the } \\
\text { null } \\
\text { Hypothesis }\end{array}$} & FUTA & 733.44 \\
\hline & & & & OAU & 843.63 \\
\hline & & & & UI & 1207.46 \\
\hline $\begin{array}{l}\text { gardens among the } \\
\text { Federal }\end{array}$ & & & & FUOYE & 303.97 \\
\hline $\begin{array}{l}\text { Universities in the study } \\
\text { area. }\end{array}$ & & & & $\begin{array}{l}\text { FUNNAB } \\
\text { UNILAG }\end{array}$ & $\begin{array}{c}1022.45 \\
604.23\end{array}$ \\
\hline
\end{tabular}

Pairwise Comparisons of Universities

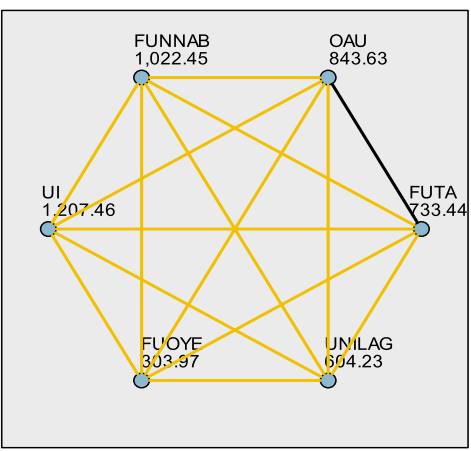

Each node shows the sample average rank of Universities.

\begin{tabular}{|lccccc|}
\hline Sample1-Sample2 & $\begin{array}{c}\text { Test } \\
\text { Statistic }\end{array}$ & $\begin{array}{c}\text { Std. } \\
\text { Error }\end{array}$ & $\begin{array}{c}\text { Std. Test } \\
\text { Statistic }\end{array}$ & Sig. & Adj.Sig. \\
\hline FUOYE-UNILAG & -300.259 & 46.637 & -6.438 & .000 & .000 \\
\hline FUOYE-FUTA & 429.475 & 47.366 & 9.067 & .000 & .000 \\
\hline FUOYE-OAU & 539.666 & 46.510 & 11.603 & .000 & .000 \\
\hline FUOYE-FUNNAB & -718.481 & 46.535 & -15.440 & .000 & .000 \\
\hline FUOYE-UI & 903.497 & 46.173 & 19.568 & .000 & .000 \\
\hline UNILAG-FUTA & 129.216 & 39.090 & 3.306 & .001 & .014 \\
\hline UNILAG-OAU & 239.407 & 38.049 & 6.292 & .000 & .000 \\
\hline UNILAG-FUNNAB & 418.222 & 38.079 & 10.983 & .000 & .000 \\
\hline UNILAG-UI & 603.238 & 37.636 & 16.028 & .000 & .000 \\
\hline FUTA-OAU & -110.191 & 38.938 & -2.830 & .005 & .070 \\
\hline FUTA-FUNNAB & -289.006 & 38.968 & -7.416 & .000 & .000 \\
\hline FUTA-UI & -474.022 & 38.535 & -12.301 & .000 & .000 \\
\hline OAU-FUNNAB & -178.815 & 37.923 & -4.715 & .000 & .000 \\
\hline OAU-UI & -363.831 & 37.478 & -9.708 & .000 & .000 \\
\hline FUNNAB-UI & 185.016 & 37.510 & 4.933 & .000 & .000 \\
\hline
\end{tabular}

Each row tests the null hypothesis that the Sample 1 and Sample 2

distributions are the same.
Asymptotic significances (2-sided tests) are displayed. The significance level

Figure 2. Result of a Pairwise customisedKruskal-Wallis post-hoc test for the perception of Quality of Zoological gardens in the study area. 


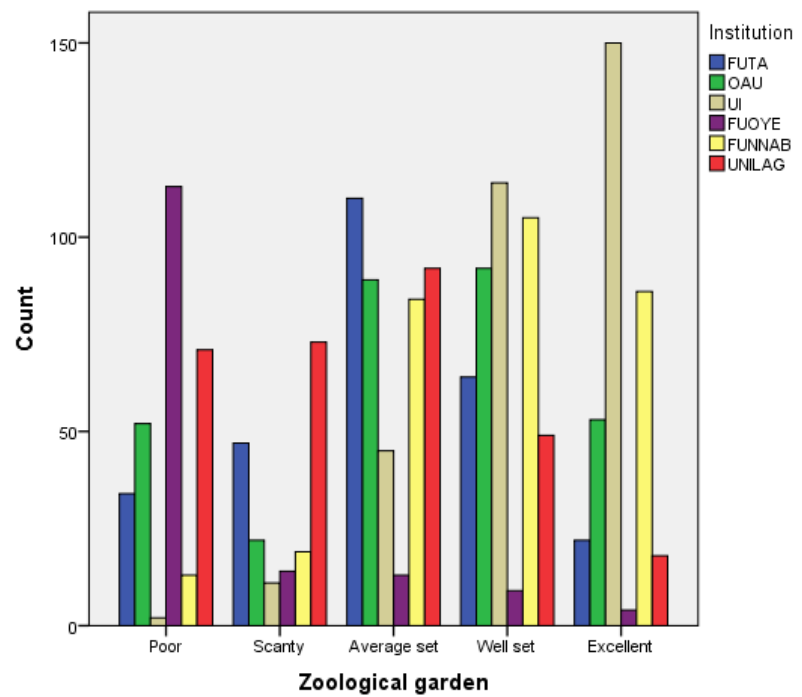

Figure 3. Differences in the perceptions of qualities of Zoological gardens among the six Federal Universities' campuses in Southwest Nigeria.

3.3 Impact of Status of Users on Perception of Quality of Zoological gardens

Tables 4 and 5 show the result of the Cramer's $V$ test between the status of the users and their perception of qualities of the Zoological gardens. Only discipline (Cramer's V=0.110, $\mathrm{p}=0.000<0.005$ ) has significant impact at $95 \%$ confidence level.

Table 4. Relationship between status (nominal variables) of the users and their perception of qualities of the Zoological gardens.

\begin{tabular}{lll}
\hline Status of users & Cramer's V Value & Approx. Sig. ( $p$ value) \\
\hline Gender & 0.046 & 0464 \\
Discipline & $\mathbf{0 . 1 1 0}$ & $\mathbf{0 . 0 0 0}$ \\
Impairment & 0.049 & 0.447 \\
Car ownership & 0,065 & 0.135 \\
\hline
\end{tabular}

Table 5. Relationship between status (ordinal variables) of the users and their perception of qualities of the Zoological gardens.

\begin{tabular}{lll}
\hline Status of users & Kendal tau Value & Approx. Sig. (p value) \\
\hline Age & $-0.007 \mathrm{c}$ & 0.717 \\
Educational status & $-0.025 \mathrm{~b}$ & 0.240 \\
Class level & $-0.001 \mathrm{c}$ & 0.948 \\
\hline
\end{tabular}

b: Kendal tau b because of the square contingency table

c: Kendal tau c because of the rectangular contingency table

\subsection{Factors Influencing Users' Satisfaction}

\subsubsection{Use Factors}

Cramer's V test was carried out to examine the 'use factors' influencing the satisfaction of users with the UZGs. The use factors are extrinsic to the UZGs since they have to do with the users themselves on how they use the gardens. The four use factors are common period of use, common purpose of use, mode of pedestrian use and hindrances to use. Table 6 shows that common period of use and mode of pedestrian use do not have significance on the perception of quality of the UZG (Cramer's V=0.087, $\mathrm{p}=0.005$ ). Figure 4 shows that those who use the Zoological gardens for academic purposes had higher perceptions of their qualities than other users. 


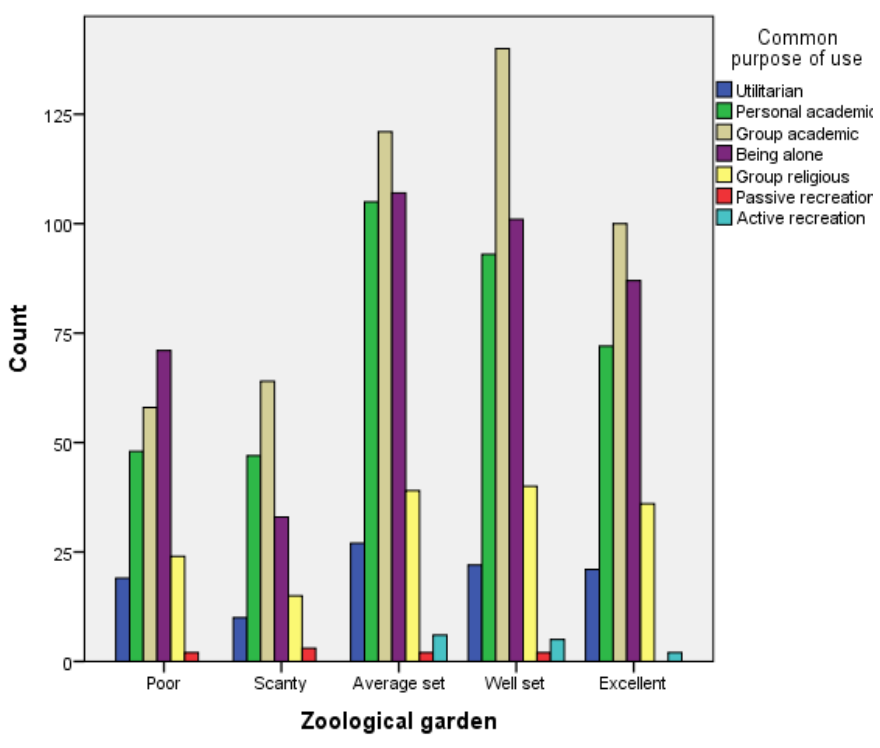

Figure 4. Influence of common purpose of use on the perception of quality of zoological gardens in federal universities in the South-west Nigeria.

Figure 5 shows that the perception of quality of Zoological gardens is influenced by the purpose of use. Those that use them for group academic, being alone and personal academic purpose perceive the gardens to be of higher quality than utilitarian and passive recreation.

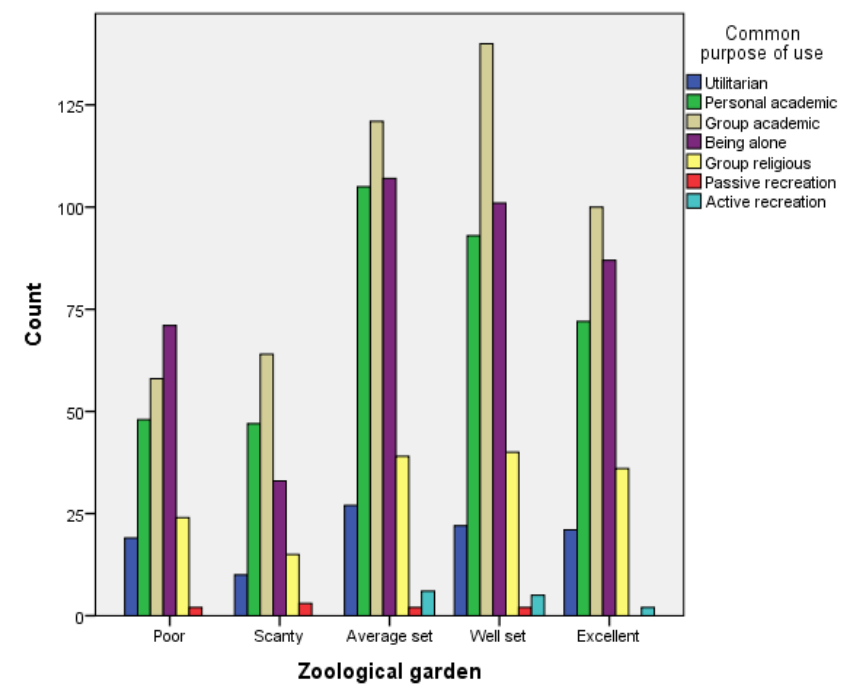

Figure 5. Influence of common purpose of use on the perception of quality of Zoological gardens in Federal Universities in South-west Nigeria.

Furthermore, hindrances to use significantly influenced the perceptions of qualities of the UZGs at 0.01 (99\%) confidence level as shown in Table 6. Figure 6 shows that inclement weather and lack of visual privacy accounts for perception of qualities.

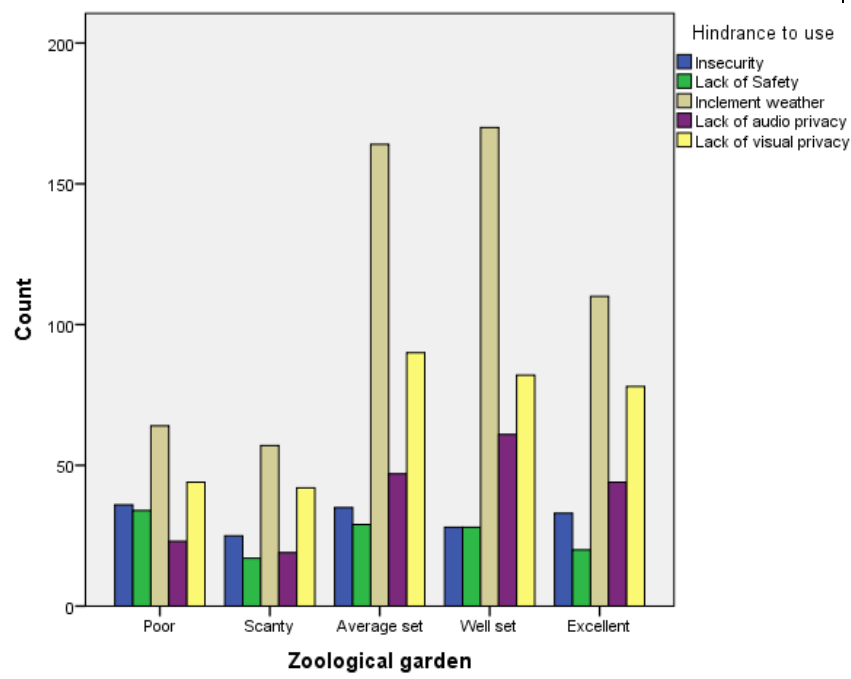

Figure 6. Influence of hindrances to use on the perception of quality of Zoological gardens in Federal Universities in the South-west Nigeria.

Table 6. Use factors influencing satisfaction of users with the university. Zoological gardens in the study area.

\begin{tabular}{lll}
\hline Use factors & Cramer's & $p$-value \\
& $\vee$ & \\
\hline Common period of visit & 0.058 & 0.421 \\
Common purpose of visit & 0.070 & 0.192 \\
Mode of pedestrian use & 0.058 & 0.181 \\
Hindrances to use during visit & $\mathbf{0 . 0 9 3}$ & $\mathbf{0 . 0 0 0}$ \\
\hline
\end{tabular}

\subsubsection{Cognitive Factors}

Cognitive satisfaction factors are intrinsic to the UZGs since they have to do with the spaces. The other intrinsic factors are social, spatial and affective factors. A Spearman's rank-order correlation was run to determine the relationship between 1759 users' satisfaction with four cognitive factors (coherence, legibility, complexity and mystery) and perceptions of qualities of the UZGs, both measured in ordinal scales. There were strong, positive correlations between satisfaction with the cognitive factors and perceptions of qualities of the UZGs which was statistically significant as follow: coherence: $r_{s}=.355, p=$ .000; complexity: $r_{s}=.349, p=.000 ;$ mystery: $r_{s}=$ $.315, p=.000$; and legibility: $r_{s}=.314, p=.000$, in descending order, as shown in Table 7 and Figure 7. 


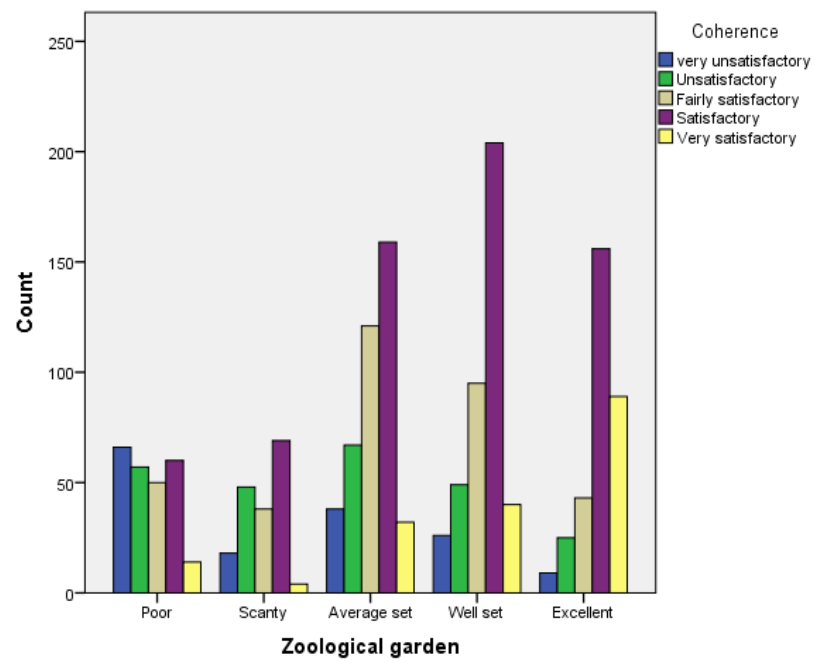

Figure 7. Influence of satisfaction with coherence on the perception of quality of Zoological gardens in Federal Universities in the South-west Nigeria

\subsubsection{Social Factors}

As shown in Table 7, in view of the high sample size, there were strong, positive correlations between satisfaction with the social factors and perceptions of qualities of the Zoological gardens which was statistically significant at $0.01(99 \%)$ confidence level. Safety $\left(r_{s}=.330, p=\right.$ .000) has the highest correlation coefficient followed by social interaction spaces $\left(r_{s}=.312\right.$, $p=.000)$, security $\left(r_{s}=.277, p=.000\right)$, conviviality and audio privacy $\left(r_{s}=.273, p=.000\right)$, visual privacy $\left(r_{s}=.268, p=.000\right)$, and open space for personal meditation $\left(r_{s}=.252, p=.000\right)$ in descending order.

Table 7. Factors influencing users' satisfaction with the University Zoological gardens in the study area.

\begin{tabular}{clcc} 
Table 7. Factors influencing users' satisfaction with the University Zoological gardens in the study area. \\
\hline & Factors & Spearman & $p$ \\
& Correlation & value \\
\hline Cognitive factors & Coherence & 0.355 & 0.000 \\
& Legibility & 0.314 & 0.000 \\
& Complexity & 0.349 & 0.000 \\
Social factors & Conviviality & 0.315 & 0.000 \\
& Social interaction spaces & 0.273 & 0.000 \\
& Visual privacy & 0.312 & 0.000 \\
& Audio privacy & 0.268 & 0.000 \\
& Open space for being & 0.252 & 0.000 \\
& alone & & 0.000 \\
& Safety & 0.330 & 0.000 \\
& Security from crime/fear of & 0.277 & 0.000 \\
& crime & & \\
Spatial factors & Accessibility & 0.285 & 0.000 \\
& Proximity & 0.266 & 0.000 \\
& Walk-ability & 0.261 & 0.000 \\
& Connectedness & 0.294 & 0.000 \\
& Continuity & 0.265 & 0.000 \\
Affective factors & Convenience & 0.314 & 0.000 \\
& Relaxing-ability & 0.297 & 0.000
\end{tabular}

\subsubsection{Spatial Factors}

Six spatial satisfaction factors were investigated through Spearman's correlation as determinants of the perception of quality of the UZGs as shown in Table 7. Convenience $\left(r_{s}=\right.$ $.314, p=.000)$ has the highest correlation coefficient and continuity $\left(r_{s}=.265, p=.000\right)$ the least. Invariably, zoological gardens should be designed for convenience to enhance the movement of users from one section to another. However, they are not expected to be at continuity with other UCOS at the main activity areas but should be secluded since the proximity correlation coefficient is also low $\left(r_{s}=\right.$ $.266, p=.000$ ) compared with others. On the whole, the higher the satisfaction with the spatial factors, the higher the perception of quality of the UZGs.

\subsubsection{Affective Factors}

Table 7 shows the correlation coefficients between perceptions of qualities and affective satisfaction factors of UZGs. The results suggest that fascinating-ability $\left(r_{s}=.346, p=.000\right)$ is the most important affective factor, followed by pleasantness $\left(r_{s}=.323, p=.000\right)$ while recuperative-ability $\left(r_{s}=.252, p=.000\right)$ is the least. This pattern suggests that satisfaction of users with the UZGs is premised upon specific affective factors which should be built into their designs. 


$\begin{array}{lll}\text { Fascinating-ability } & 0.346 & 0.000 \\ \text { Enjoy-ableness } & 0.310 & 0.000 \\ \text { Restfulness } & 0.265 & 0.000 \\ \text { Inviting-ability } & 0.292 & 0.000 \\ \text { Inspiring-ability } & 0.293 & 0.000 \\ \text { Beautifulness } & 0.321 & 0.000 \\ \text { Exciting-ability } & 0.313 & 0.000 \\ \text { Recuperative-ability } & 0.252 & 0.000 \\ \text { Therapeutic-ability } & 0.229 & 0.000 \\ \text { Restorative-ability } & 0.261 & 0.000 \\ \text { Pleasantness } & 0.323 & 0.000 \\ \text { Comfortableness } & 0.283 & 0.000\end{array}$

\subsection{Testing of Hypothesis Ho2:Influence of Satisfaction Factors on Perceptions of Quality}

Ordinal regression analysis was carried out to estimate the 30 intrinsic satisfaction factors (cognitive, social, spatial and affective factors) influencing the perception of quality of the UZGs. Accordingly, model fitting information and Pseudo R-Square were generated as shown in Table 8. The dependent variable which measures the perception of quality is the UZGs. UZGs is equal 1 if the respondent perceives the garden as poor, 2 as scanty, 3 as averagely set, 4 as well set and 5 as excellent. since dependent/outcome variable is ordinal, and the satisfaction factors, SF (independent/predictors) are measured as ordinal variables (SF is equal 1 if the respondent is very unsatisfied with the performance of the open space based on the SF under consideration, 2 for unsatisfactory, 3 for fairly satisfactory, 4 for satisfactory and 5 for very satisfactory) the ordinal regression model is used to estimate the factors which influence satisfaction of the users. Only the 30 satisfaction factors that are intrinsic to the UZGs were included in the model. Use factors were excluded since they are extrinsic to the UZGs.

The results in the Model indicate that as the ratings of the satisfaction factors increase, the perception of quality increases and the model is significant at the .01 level $199 \%$ confidence level). This is for Cox and Snell (theoretical maximum value of less than 1), Nagelkerke (adjusted version of the Cox and Snell $R^{2}$ to cover the full range from 0 to 1) and McFadden's (based on the log-likelihood kernels for the intercept-only model and the full estimated model) Pseudo $\mathrm{R}^{2}$, since it is not possible to compute a single $\mathrm{R}^{2}$ statistic that has all of the characteristics in the linear regression model for regression models based on ordinal data (Tjur, 2009). According to Cox and Snell Pseudo R2, Table 8 shows that the model predicts that the satisfaction factors, SF [Chisquare=3866.018, $d f=245, \quad p=0.000,2$ Log Likelihood final $=102.613$ ] accounts for $95.0 \%$ of the variance in the perception of quality of UZGs.

Table 9 shows the Parameter estimates (beta coefficients) of the intrinsic factors influencing users' satisfaction. The estimates are based on scale models which depend on the main and interaction effects. Three intrinsic satisfaction factors are the best predictors of perception of quality as highlighted. Table 9 suggests that satisfaction with legibility $(0.574)$ is the best predictor of perception of quality of Zoological gardens. This is followed consecutively by beautifulness (0.331) and walk-ability (0.325). Furthermore, satisfaction with social interaction space $(0.434)$ is a better predictor of perception of quality, being the highest, than restfulness (0.423) and walk-ability (0.356) consecutively.

Table 8. Ordinal regressions of perception of quality of open spaces (dependent/outcome) and factors determining the satisfaction of the users (independent/predictors) in Federal Universities in South-west Nigeria

\begin{tabular}{|c|c|c|c|c|c|c|c|c|}
\hline \multirow{2}{*}{$\begin{array}{c}\text { University } \\
\text { Zoological } \\
\text { gardens. }\end{array}$} & \multicolumn{5}{|c|}{ Model Fitting Information } & \multicolumn{3}{|c|}{ Pseudo R-Square } \\
\hline & Model & $\begin{array}{c}-2 \text { Log } \\
\text { Likelihood }\end{array}$ & $\begin{array}{c}\text { Chi- } \\
\text { Square }\end{array}$ & Df & Sig. & $\begin{array}{c}\text { Cox \& } \\
\text { Snell }\end{array}$ & $\begin{array}{c}\text { Nagelker } \\
\text { ke }\end{array}$ & $\begin{array}{c}\text { McFadd } \\
\text { en }\end{array}$ \\
\hline \multirow[t]{2}{*}{$\begin{array}{c}\text { Zoological } \\
\text { gardens }\end{array}$} & $\begin{array}{c}\text { Intercept } \\
\text { Only }\end{array}$ & 3968.631 & & & & & & \\
\hline & Final & 102.613 & 3866.018 & 245 & .000 & .949 & .992 & .950 \\
\hline
\end{tabular}

Link function: Logit. 
Table 9. Parameter estimates of the factors influencing users' satisfaction with the Federal Universities campus open spaces in the study area.

\begin{tabular}{|c|c|c|}
\hline $\begin{array}{l}\text { Satisfaction } \\
\text { factors }\end{array}$ & Components & $\begin{array}{l}\text { Parameter } \\
\text { estimates }\end{array}$ \\
\hline \multirow{4}{*}{$\begin{array}{l}\text { Cognitive } \\
\text { factors }\end{array}$} & Coherence & -0.558 \\
\hline & Legibility & 0.574 \\
\hline & Complexity & -0.342 \\
\hline & Mystery & 0.060 \\
\hline \multirow{7}{*}{$\begin{array}{l}\text { Social } \\
\text { factors }\end{array}$} & Conviviality & 0.165 \\
\hline & Social interaction spaces & 0.255 \\
\hline & Visual privacy & 0.052 \\
\hline & Audio privacy & -0.214 \\
\hline & Open space for being alone & 0.158 \\
\hline & Safety & -0.224 \\
\hline & Security from crime/fear of crime & 0.112 \\
\hline \multirow{6}{*}{$\begin{array}{l}\text { Spatial } \\
\text { factors }\end{array}$} & Accessibility & 0.156 \\
\hline & Proximity & -0.286 \\
\hline & Walk-ability & 0.325 \\
\hline & Connectedness & -0.542 \\
\hline & Continuity & 0.186 \\
\hline & Convenience & -0.137 \\
\hline \multirow{13}{*}{$\begin{array}{l}\text { Affective } \\
\text { factors }\end{array}$} & Relaxing-ability & -1.442 \\
\hline & Fascinating-ability & -0.316 \\
\hline & Enjoy-ableness & 0.147 \\
\hline & Restfulness & 0.280 \\
\hline & Inviting-ability & 0.096 \\
\hline & Inspiring-ability & -0.219 \\
\hline & Beautifulness & 0.331 \\
\hline & Exciting-ability & 0.043 \\
\hline & Recuperative-ability & 0.093 \\
\hline & Therapeutic-ability & -0.262 \\
\hline & Restorative-ability & -0.098 \\
\hline & Pleasantness & 0.095 \\
\hline & Comfortableness & 0.062 \\
\hline
\end{tabular}

3.6 Evidence-based Design Framework for University Zoological Gardens

Figure 8 shows the framework developed for the design of UZGs. While all the satisfaction factors are important to the perception of quality, satisfaction with legibility is the most crucial, followed by beautifulness, walk-ability and hindrances to use. 


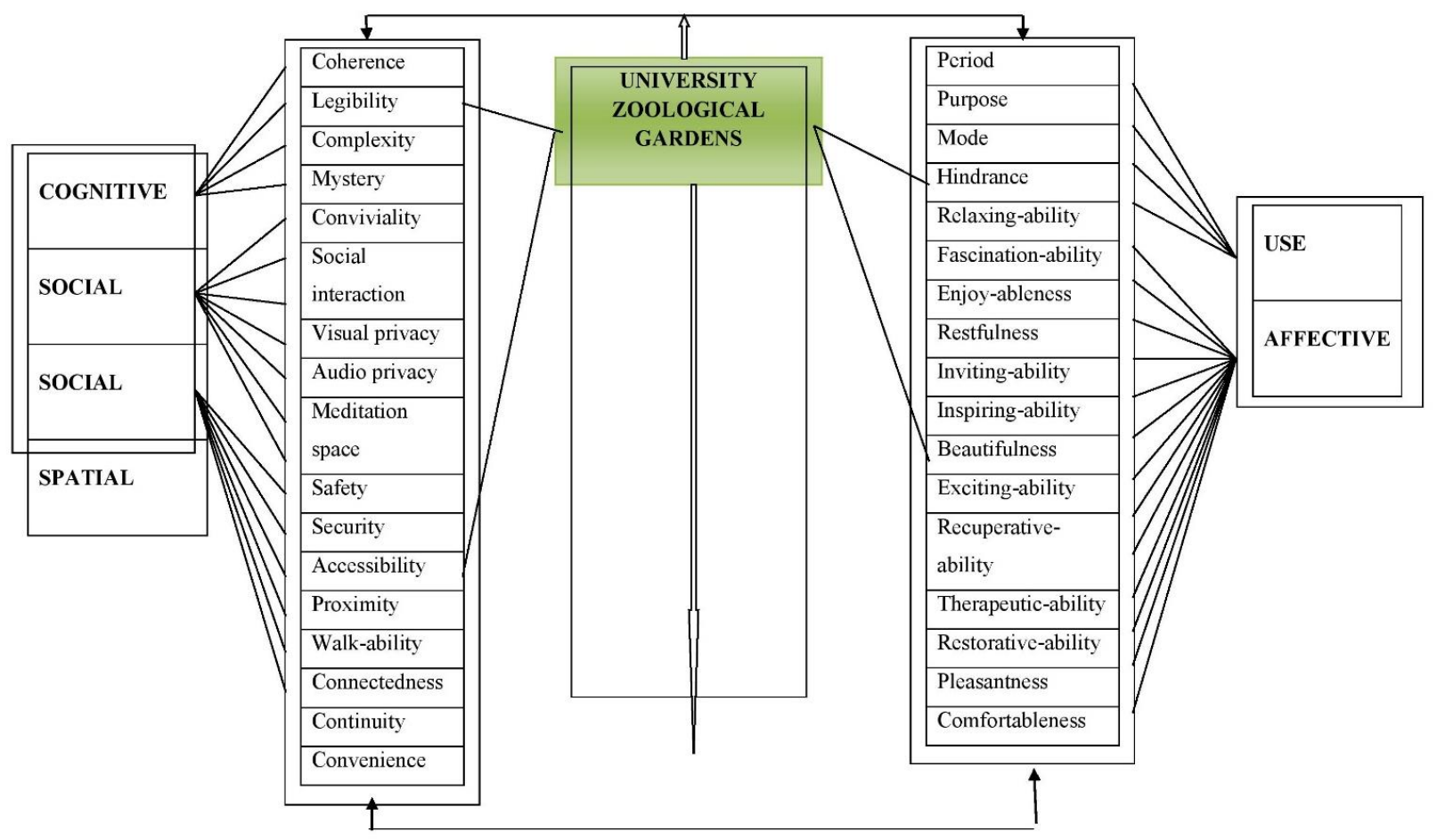

Figure 8. EBD framework for UZGs.

\section{Discussion of Findings}

An assessment of the UZGs in all the six Federal Universities in South-west Nigeria towards the formulation of EBD framework was carried out in this study. According to the findings of this study, the distributions of the users' status suggest both peculiarities and generalisations. The peculiar needs of the genders, impairment groups, disciplines and age groups are central to the successful provision of UZGs on the campuses. UZGs are discovered to be primarily used for academic activities and also for recreation and these differ from one discipline to another. This suggests that the UZGs are learning spaces and constellation arenas for psychological wellbeing in high disproportion compared with other uses. The UI Zoological garden was perceived to be of the best quality possibly due to the Zoology programme in the university, the garden being a vital learning space. Also, the UI Zoological garden doubles as a vital recreation facility of the city's and region's teaming urban populations and therefore may be admirable as the minimum standard for the design of UZGs in the study area. Those who use the Zoological gardens in the study area for academic purposes had higher perceptions of quality than other users. Furthermore, satisfaction factors are important to successful UZG delivery. While safety is a primary satisfaction factor, result implies that legibility is the most primary cognitive factor for designing perceptible high quality Zoological gardens. This confirms the Kaplan and Kaplan's (1989) information processing matrix of landscapes. The framework suggests that legibility, beautifulness, walkability and hindrances to use are 'hot spots' satisfaction factors of UZGs.

\section{Conclusion and Recommendation}

This work has established that UZGs are important to the effective functional activities on the campuses. Their design should therefore be evidence-based. Evidence-based design can only be carried out through the instrument of post-occupancy evaluation (POE) for longterm benefit to serve as a feedback into the design process. For POE to produce this desired goal and wider-relevance application, geographical spread is germane. Accordingly, the set aim of this study on the Federal Universities campuses in South-west Nigeria can be appraised to have been achieved. However, the operational quality of the formulated framework can be appraised by engaging it as design tool-kit generally for all formally designable campuses of institutions of higher learning but primarily for university campuses in the study area. Also, medium term benefit can be achieved by applying the policy framework for minor adjustments of existing UZGs for better users' satisfaction.

Contextually, the study was limited in scope to Federal Universities. Further work can be carried 
out inclusively and exclusively with other proprietorships of universities within and outside the South-west Nigeria. Such can be for comparative purposes or case studies and can include considerations like maintenance and management of UZGs. In term of methodological approach, since this work is limited to quantitative research design on crosssectional basis, qualitative and/or mixed method paradigms that can also be longitudinal can be further engaged on different spatial scales.

On the whole, the perception of quality is related to the satisfaction factors such that as the ratings of the satisfaction factors increase, the perception of quality increases. The satisfaction factors therefore account for the significant differences in the perceptions of qualities of the UZGs among the six Federal Universities in the study area. The satisfaction factors that account for the perceptions of qualities of UI Zoological should be programmed into the design of UCOS to avoid the misuse of spaces and best decisions to be taken during the design process.

\section{Acknowledgments}

This research did not receive any specific grant from funding agencies in the public, commercial, or non-for-profit sectors.

\section{References}

Abu-Ghazzeh, T.M. (1999). Communicating Behavioral Research to Campus Design: Factors Affecting the Perception and Use of Outdoor Spaces at the University of Jordan Environment and Behaviour, 31 (6); 764804. https://doi.org/10.1177/00139169921972344 Adedeji, J.A. and Fadamiro, J.A. (2012). Affective Correlates of Landscapes for Passive Recreation in Institutional Campuses, Ogbomoso, Nigeria Journal of Biourbanism.
JBU
II(1)
77-93.

http://www.biourbanism.org/journal-of-

biourbanism-n-12012/

Adedeji, J.A., Bello, Y. O. and Fadamiro, J.A. (2011). Thermal Adaptation, Campus Greening and Outdoor Use in LAUTECH Campus, Ogbomoso, Nigeria. Dimensi, Journal of Architecture and Built Environment, 38(2):63-72.

https://doi.org/10.9744/dimensi.38.2.63-72

Alan, J. C. (2005). Dictionary of Landscape Architecture and Construction. New York: McGraw Hill.
Landscape-Architecture-Construction-

Christensen/dp/0071441425

Ambler, T., Webb, R., Hummell, E., Robertson, G. and Bailey, S. (2013). Exploring Students' Experiences of Learning in Outdoor Places on a University Campus. Research and

Development in Higher Education: The Place of Learning and Teaching, 36:11-25. http://www.herdsa.org.av/publications/confere nce-proceedings/research-and-developmenthigher-education-place-learning-and-1

Arenibafo, F. (2016). The Transformation of Aesthetics in Architecture from Traditional to Modern Architecture: A case study of the Yoruba (southwestern) region of Nigeria. Contemporary Urban Affairs (JCUA), 1 (1), 35-44. Doi: $10.25034 / 1761.1(1) 35-44$.

https://doi.org/10.25034/1761.1(1)35-44

Asadi-Shekari, Z., Moeinaddini, M. and Shah, M.Z. (2014) A pedestrian level of service method for evaluating walking facilities on campus streets. Land Use Policy, 38:175-193, May. http://www.istiee.org/te/papers/N67/P02_67_20 18a.pdf

Aydin, D. and Ter, U. (2008). Outdoor Space Quality: A Case Study of a University Campus Plaza. Archnet-IJAR, International Journal of Architectural Research, 2(3), 189-203 November.

https://www.researchgate.net/publication/2657 1407 Outdoor_Space_Quality_Case_Study_of_a University Campus Plaza Regular Paper

Couper,R. (2013). Placing the Origins of the Zoo An Architectural Analysis of the Metamorphosis of the Menagerie into the Zoological Garden" in Proceedings of the Society of Architectural Historians, Australia and New Zealand: 30, Open, edited by Alexandra Brown and Andrew Leach (Gold Coast, Qld: SAHANZ, 2013), vol. 1, p 235-246. https://www.griffith.edu.au/_data/assets/pdf_fi le/0028/349363/S04_01_Couper_Placing-theOrigins-of-the-Zoo.pdf

Cubukcu. E. and Isitan, Z. N. (2011). Does Student Behavior Differ in Relation to Perception/

Evaluation of Campus Environments? A Postoccupancy Research in Two University Campuses Gazi University Journal of

Science, 24(3):547-558.

http://dergipark.gov.tr/download/article-

file/83147

Dober, R. P. (2000). Campus Landscape: Functions, Forms, Features. New York: John Wiley \& Sons, Inc.

https://www.wiley.com/en-

us/Campus+Landscape\%3A+Functions\%2C+For $\underline{\mathrm{ms} \% 2 \mathrm{C}+\text { Features-p-9780471353560 }}$ 
Fadamiro, J. A. and Adedeji, J. A. (2014). Recreational Experiences in Parks and Gardens,

Ibadan, Nigeria, Journal of Place Management and Development, 7 (1):5 - 26. https://doi.org/10.1108/jpmd-1 1-2013-0023

Faleyimu, O. I. and Agbeja, B. O. (2012). Constraints to Forest Policy Implementation in the Southwest Nigeria: Causes, Consequences and Cure. Journal of Resources and Environment, 2(2), 37-44. https://doi.org/10.5923/j.re.20120202.06

14Geddes, P. (1906) Civics as Applied Sociology, Sociological Papers, Vol. II: 57-111. http://www.archive.org/stream/civicsasapplied s13205gut/13205-8.txt

Gehl, J. (1987) Life between Buildings: Using public spaces, New York: Van Nostrand Reinhold. https://www.amazon.com/Life-BetweenBuildings-Using-Public/dp/1597268275

Gewaily, M. (2010). Visitor Experience in Zoo Design: Design Guidelines for Giza Zoo. A Thesis submitted to the Graduate Faculty of the University of Georgia in Partial fulfilment of the requirements for the degree of Master of Landscape Architecture, Athens, Georgia. https://getd.libs.uga.edu/pdfs/gewaily marwa 201005 mla.pdf

Heitor, T., Nascimento, R., Tomé, A. and Medeiros, V. (2013). (In) Accessible Campus: Space Syntax for Universal Design. In Proceedings of the Ninth International Space Syntax Symposium Edited By Y O Kim, H T Park and K W Seo, Seoul: Sejong University, 2013. http://www.sss9sejong.or.kr/proceedings/proce edings 1.asp

Helsper, H., Johnson, M., Johnson, T., Rubba, D. and Steiner, F. (1990). The Auraria campus: An Example of American landscape design. Landscape and Urban Planning, 19(1):1- 16. https://doi.org/10.1016/0169-2046(90)90032-W

Lefebvre, H. (1991). The production of space (D. Nicholson-Smith, Trans.). Oxford, UK: Blackwell. https://monoskop.org/images/7/75/Lefebvre_H enri The Production_of Space.pdf

Lyndon, D. (2005). Caring for Places: Caring for Thought. Places, 17(1), 3. https://escholarship.org/uc/item/69×027m3

McHarg, I. (1969). Design with Nature. New York: Natural History Press. https://www.amazon.com/Design-Nature-lan-LMcHarg/dp/047111460X

Mumford, L. (1938). The Culture of Cities. New York: Harcourt,
https://monoskop.org/images/5/5a/Mumford_L ewis The_Culture_of_Cities.pdf

Mumford, L. (1969). The Philosophy of Urban Open Space. In W. N. Seymour, Small Urban Spaces (pp. 13-22). New York: New York University Press. https://lib.ugent.be/en/catalog/rug01:00096496 $\underline{3}$

Munoz, S.A. (2009). Children in the outdoors: A literature review. Sustainable Development Research Centre. Retrieved from http://www.educationscotland.gov.uk

25Nia, H. A. and Suleiman, Y. H. (2017). Aesthetics of Space Organization: Lessons from Traditional European Cities. Journal of Contemporary Urban Affairs (JCUA), 2(1), 66-75. https://doi.org/10.25034/ijcua.2018.3657

Payne, G (2007). Social divisions, social mobilities and social research: Methodological issues after 40 years. Sociology, 41, 901-915. https://doi.org/10.1177/0038038507080444

Rapoport, A. (2004). Kültür, Mimarlık, Tasarım [Culture, Architecture, Design] . Translation SelcukBatur, YEM Press, Istanbul, Turkey. https://www.kitapyurdu.com/kitap/kulturmimarlik-tasarim/66107.html

Swensen, G. and Stenbro, R. (2013). Industrial Heritage as Qualifying Elements in Urban Landscapes. ATINER Conference Paper Series No: PLA2013-0690. http://www.atiner.gr/papersubjects/architecture-papers.htm

Sahraiyanjahromi, F. (2017). Aesthetic Fitness of New Buildings in Historic Environment: Compatibility and Contextual Design. Contemporary Urban Affairs (JCUA), 2(1), 13-21. https://doi.org/10.25034/ijcua.2018.3652

Venkat, U. (2011) .Building a Sense of Community on Campus through Physical Design. A Thesis Submitted To the Graduate Faculty of The University of Georgia in Partial Fulfilment of The Requirements for the Degree Master of Landscape Architecture. https://athenaeum.libs.uga.edu/handle/10724/ 27629

Watson, C. and Thomson, K. (2005). Bringing postoccupancy evaluation to schools in Scotland. Evaluating Quality in Educational Facilities. OECD. Available online at http://www.oecd.org

Wolf, R. L. AndTymitz, B. L. (1979). Do giraffes ever sit: A study of visitor perceptions at the National Zoological Park, Smithsonian Institution. Washington, DC: Smithsonian. https://eric.ed.gov/?id=ED 196769

Woolley, H. (2003). Urban Open Spaces. London: Spon

Press. 